\title{
Risk management frameworks: supporting the next generation of Murray-Darling Basin water sharing plans
}

\author{
G. M. PODGER ${ }^{1}$, S. M. CUDDY ${ }^{1}$, L. PEETERS ${ }^{2}$, T. SMITH ${ }^{1}$, R. H. BARK ${ }^{3}$, \\ D. C. BLACK ${ }^{1} \&$ P. WALLBRINK ${ }^{1}$ \\ 1 CSIRO Water for a Healthy Country Flagship, Canberra, Australia \\ geoff.podger@csiro.au \\ 2 CSIRO Land and Water, PMB No. 2, Glen Osmond, South Australia, Australia \\ 3 CSIRO Ecosystem Sciences, Dutton Park, Queensland, Australia
}

\begin{abstract}
Water jurisdictions in Australia are required to prepare and implement water resource plans. In developing these plans the common goal is realising the best possible use of the water resources maximising outcomes while minimising negative impacts. This requires managing the risks associated with assessing and balancing cultural, industrial, agricultural, social and environmental demands for water within a competitive and resource-limited environment. Recognising this, conformance to international risk management principles (ISO 31000:2009) have been embedded within the Murray-Darling Basin Plan. Yet, to date, there has been little strategic investment by water jurisdictions in bridging the gap between principle and practice. The ISO 31000 principles and the risk management framework that embodies them align well with an adaptive management paradigm within which to conduct water resource planning. They also provide an integrative framework for the development of workflows that link risk analysis with risk evaluation and mitigation (adaptation) scenarios, providing a transparent, repeatable and robust platform. This study, through a demonstration use case and a series of workflows, demonstrates to policy makers how these principles can be used to support the development of the next generation of water sharing plans in 2019. The workflows consider the uncertainty associated with climate and flow inputs, and model parameters on irrigation and hydropower production, meeting environmental flow objectives and recreational use of the water resource. The results provide insights to the risks associated with meeting a range of different objectives.
\end{abstract}

Key words risk management; water resource planning; risk assessment, water management modelling, eWater Source

\section{WATER PLANNING IN AUSTRALIA}

Water planning has a long history in Australia. The National Water Commission (NWC 2011, p.2) describes water planning as "a process for transparently determining the distribution of water resources over time. It is the central mechanism used by (Australian) governments and communities in making water management and allocation decisions to meet specific productive, environmental and social objectives." Some of the advantages of such planning arrangements are that "statutory water plans provide security to all water users through clearly defined entitlements to a share of water. Further, water planning is a participatory process that allows for community input to government decision making in relation to the management of water resources in their local area. Water planning is particularly important for managing Australia's water resources effectively throughout the extremes in wet and dry climatic conditions and is critical where resources are contested" (NWC 2011, p. 3). In all water plans, the common goal is to realise the best (however that may be defined) use of the water resource, by seeking to achieve maximum benefit with minimum negative impacts. This requires managing the risks associated with assessing and balancing cultural, industrial, agricultural, social and environmental demands for water within a competitive and resource-limited environment. Recognising this, conformance to international risk management principles (ISO 31000:2009) has been embedded within the recently legislated Murray-Darling Basin Plan (MDBA 2012) and future water sharing plans required under the Basin Plan are required to have regard to the same standard. Yet, to date, there has been little strategic investment by water jurisdictions in bridging the gap between the rhetoric and practice of risk management.

Most jurisdictions use a range of models to assist them in their planning. These may take the form of decision support systems, but are more typically ad hoc assessment modules with input (e.g. daily hydrographs) provided by complex river system models through which a suite of alternate water sharing proposals are configured to predict flow based impacts. Setting up the 
models to run these alternate proposals is usually non-trivial and time-consuming, resulting in limited opportunity to assess and evaluate potential consequences and their likelihood. Thus, in addition to the need to improve the planning practice, there is a need to improve the underlying modelling practice.

This paper demonstrates, through a use case and a series of workflows that link risk analysis with risk evaluation and mitigation (adaptation) scenarios, how the use of an industry-standard risk management standard (ISO 31000:2009) can benefit water resource planning. Some sensitivity analysis results are presented in preference to risk assessment results, as the emphasis is on the principles and method, not the results of the use case per se.

\section{TAILORING RISK MANAGEMENT PRINCIPLES FOR WATER PLANNING}

Risk is defined as "the effect of uncertainty on objectives" (which we interpret as the effect of uncertainty on achieving objectives), and level of risk as "a combination of consequences and the likelihoods of the consequences occurring (NOT the likelihood of the event that led to the consequences)" (Standards Australia 2009). These definitions work well in the context of water planning as they explicitly incorporate uncertainty, and move the focus from the likelihood of the drivers (e.g. climate change) to the likelihood of potential consequences.

As ISO 31000:2009 has been mandated in water planning (MDBA 2012), we have adopted it for our use case, noting that its principles (Fig. 1) align well with adaptive management principles and, just as importantly, provide an integrative framework for model design and implementation.

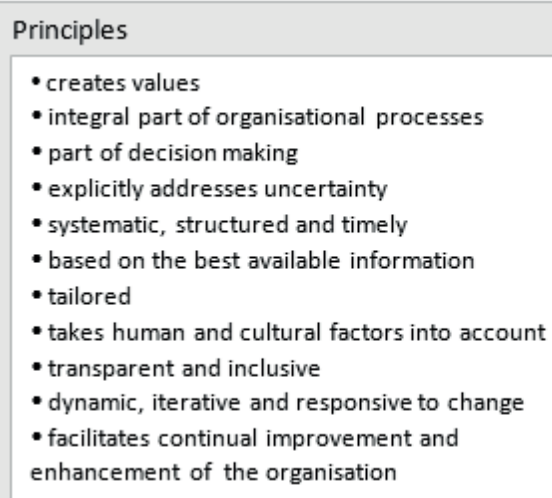

Fig. 1 The 11 principles and process steps in the ISO 31000:2009 risk management standard. Note the inclusion of stakeholders (through communication and consultation, and monitoring and review) throughout all stages of the process. Note that the feedback loops inherent in being "dynamic, iterative and response to change" are not included in this figure to provide clarity. Adapted from Standards Australia (2009).

Establishing the context in which the assessment fits within the broader resource management and planning processes is critically important. Within the water planning context, this phase is when objectives are established; stakeholder values are elicited (and respected); social, regulatory and policy constraints and drivers are identified; the biophysical environment (e.g. environmental assets, topography, land use) is described; governance arrangements are established; likelihood and consequence categories are agreed; the role of modelling is articulated; and relevant and available models are conceptualised, agreed and implemented.

To date, most water planning in Australia does not follow these steps - indeed it is our observation that many water planning exercises under-achieve due to lack of rigour and clarity in the process, and in how models are used. These risks can be minimised through early and ongoing engagement with stakeholders and the community, and good modelling practice. These principles are embodied in the ISO 31000 standard - and guidelines, such as those by Black et al. (2011) for water management modelling can be adapted to suit governance structures and modelling skills. 
Our modelling framework utilises a customised scientific workflow product (Cuddy and Fitch 2010) to provide transparency (clear separation of the modelling components), provenance (tracking of how results are produced) and plug-and-play capability (that caters for different levels of model sophistication and modelling skills).

\section{DEMONSTRATION USE CASE - THE MURRUMBIDGEE RIVER}

The demonstration use case explores the consequences (from a multi-dimensional risk perspective) of recovery of water for the environment (as legislated under the Basin Plan (MDBA 2012)) within the Murrumbidgee region of the Murray-Darling Basin (MDB) (Fig. 2). The region covers an area of $87340 \mathrm{~km}^{2}$, is highly regulated with two major storages and numerous re-regulating weirs and alluvial aquifers delivering water for power generation, irrigation, town water supply and environmental purposes. The majority of inflow occurs in the steeper eastern part of the region, with the rest of the region being flat. Major land uses are dryland crops and dryland pasture for livestock grazing ( $76 \%$ of area), with $5 \%$ under irrigated cropping (mainly cereals including rice, pasture and hay production, and some horticulture and vineyards). Native vegetation covers $17 \%$ of the area, and includes significant wetlands (including a Ramsar site) (CSIRO 2008).

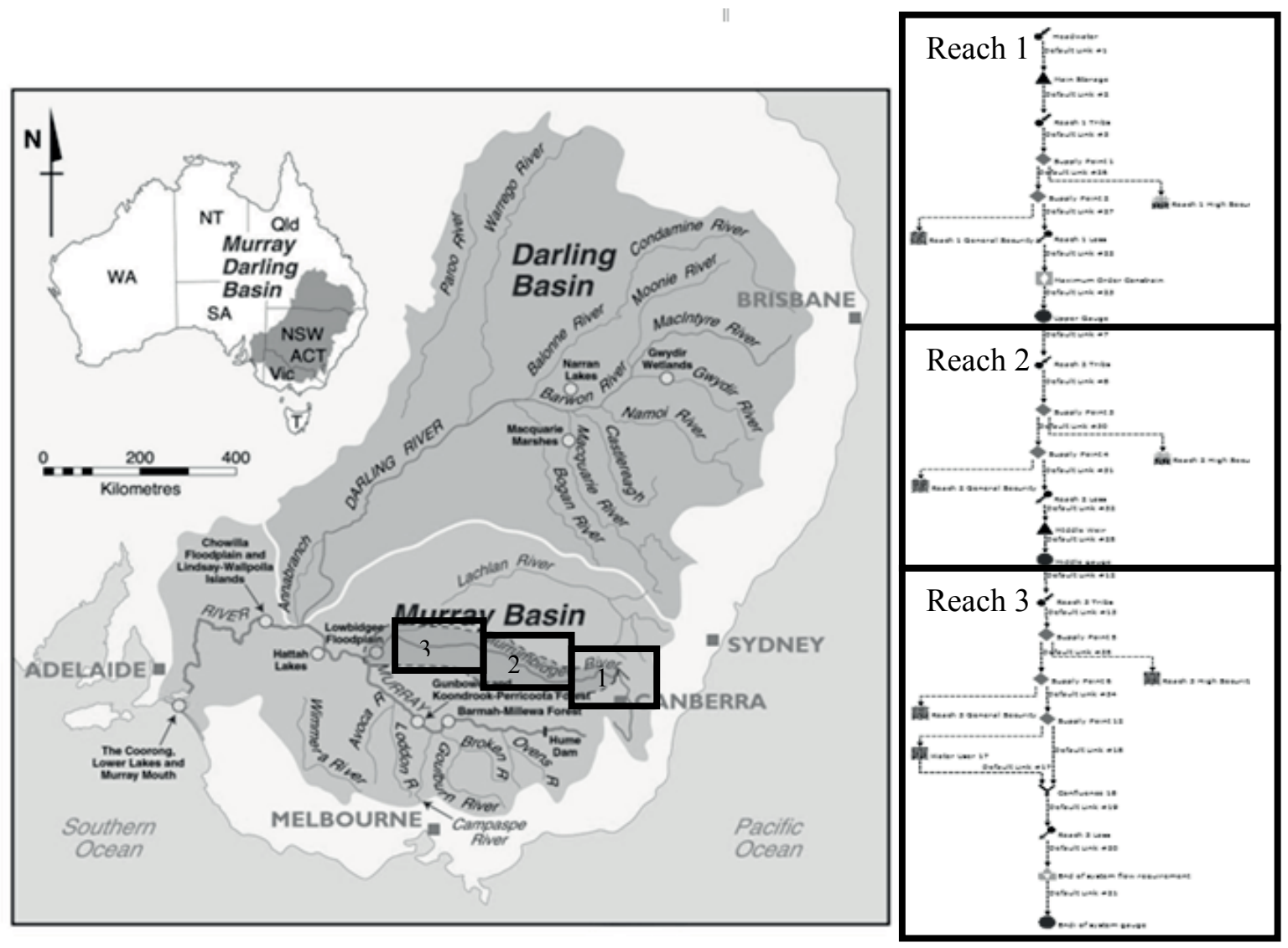

Fig. 2 Map showing the extent (indicated by shading) of the Murrumbidgee demonstration use case within the Murray-Darling Basin, and the conceptualisation of the river system into three reaches

As this is a demonstration use case and an active learning exercise, some steps in the risk management process have been adapted. Elicitation of stakeholder values and perceptions was conducted through in-house role-playing workshops. The identification of relevant models was limited to in-house tools and eWater's Source model (Welsh et al. 2013). Uncertainty has not yet been dealt with explicitly, except through sensitivity analysis.

A large number of issues were raised at the role-playing workshops. Most of these were perceived threats to livelihoods (e.g. water shortages in towns, reduced income through reduced 
irrigation water) and amenity (e.g. reduced access to swimming holes, recreational boating). All these concerns were respected and metrics/indicators identified to assess their likelihood. A set of issues was agreed for the risk assessment and these formed the body of the analysis component of the workflow and are listed in Fig. 3.

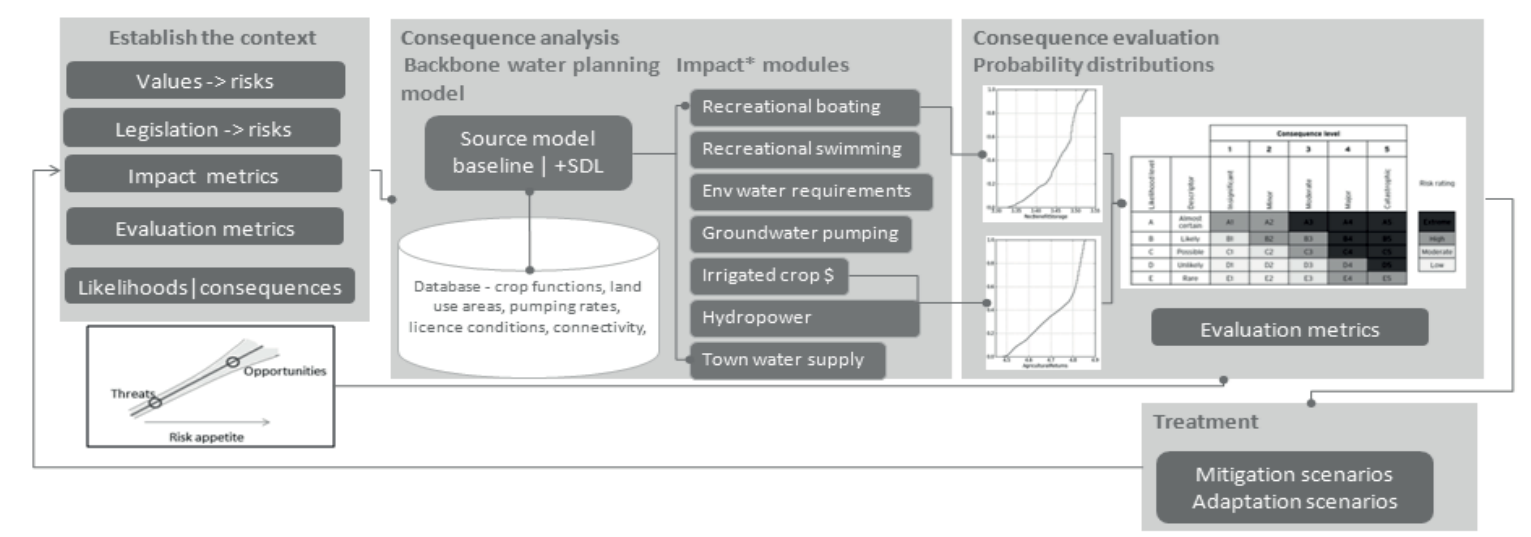

Fig. 3 Use case implementation schema. "Consequence" is used as an alternative to "risk" in this figure to communicate that risk management is about managing consequences, not just minimising risk.

\section{River system model conceptualisation}

The river system model used in the risk assessment is based on a simplified version of the Murrumbidgee River Model (Dutta et al. 2012). The simplification was driven by the need to reduce model runtime to support multi-runs for sensitivity and uncertainty analysis. The model was simplified by describing the system as three reaches (Fig. 2). In Reach 1 storages are combined, as are tributary inflows, routing and losses. Reach 2 and 3 routing, inflows and losses were derived by respectively combining routing reaches, time series inflows and loss relationships. Reach 2 and 3 also include hydraulically connected off-river wetlands. Reach 2 includes a groundsurface water interaction model. Total headwater to end-of-system travel time is 18 days $(3,6$ and 9 days - reaches 1, 2 and 3, respectively). Climate data were taken from reach representative sites.

Three types of demands are considered in the model: town water supply, irrigation supply and environmental requirement. Each reach has town water demands based on a fixed annual pattern $\left(8.8,3.0\right.$ and $1.210^{6} \mathrm{~m}^{3} /$ year). Irrigation demands are based on a reach-based aggregation of irrigation use as well as rationalising crop types. Four crop types are considered: winter grain $\left(10311 \mathrm{~km}^{2}\right)$, winter grass (also used for dairy, beef and sheep production, $\left.879 \mathrm{~km}^{2}\right)$, rice $\left(546 \mathrm{~km}^{2}\right)$, vegetables $\left(51 \mathrm{~km}^{2}\right)$ and trees $\left(246 \mathrm{~km}^{2}\right)$. Rice and vegetables are not present in Reach 1 and trees only occur in Reach 2. Area planting decisions are based on a linear regression of area versus allocation level and gross margins are obtained based on a linear relationship with area. There are environmental demands for mid and lower river wetlands and the end of system.

Two aspects of water management are considered: a $30000 \mathrm{ML} / \mathrm{d}$ order constraint on storage releases and an annual allocation system. The annual accounting system is a simplification of the complex Murrumbidgee accounting system described in the Murrumbidgee Water Sharing Plan (NSW Government 2012). The allocation system comprises high and general security order debit annual accounting schemes. Water is first allocated from the storage to high security users and then general security users. The start of the water year is 1 July with allocations updated continuously throughout the year and include allowances for minimum tributary inflows and delivery losses. At the end of the water year, accounts are reset to zero. Licence entitlements were aggregated on a reach basis.

Two socio-economic indicators have been included to indicate impacts of storage volumes on recreational usage and mid-river flows on algal blooms and thus on recreational usage. Recreational usage has three storage volume categories $(\leq 10 \%,<50 \%$ and $\geq 50 \%)$ based on visitor numbers. There are three algal bloom categories (no bloom, alert and bloom) - no bloom occurs if 
flows exceeded $1000 \mathrm{ML} / \mathrm{d}$ in the last 7 days, and alert if this is within the last 14 days otherwise bloom. Australian dollars (AUD) have been associated with loss of amenity. The sensitivity analysis described below refers to the storage recreational use.

\section{Sensitivity analysis}

Although the use case is a simplification of reality, the hydrological system represented and the socio-economic values computed based on the simulated hydrology are still complex. It is not straightforward to deduce from the model structure which driving forces or parameters will influence a model prediction most. Therefore, a limited sensitivity analysis was carried out using multipliers on the main driving forces and parameters. Sobol sequences were used to generate a quasi-random sampling of the hyperspace of multipliers. Figure 4 shows the results for the total value generated by recreation on storage reservoirs; 1000 samples were generated with different combinations of the driving forces, inflow, rainfall, evapotranspiration and baseflow, and the parameters affecting the recreational benefit value, the number of visitors when the storage reservoir is below $10 \%$ of full capacity, between 10 and $50 \%$ and above $50 \%$.
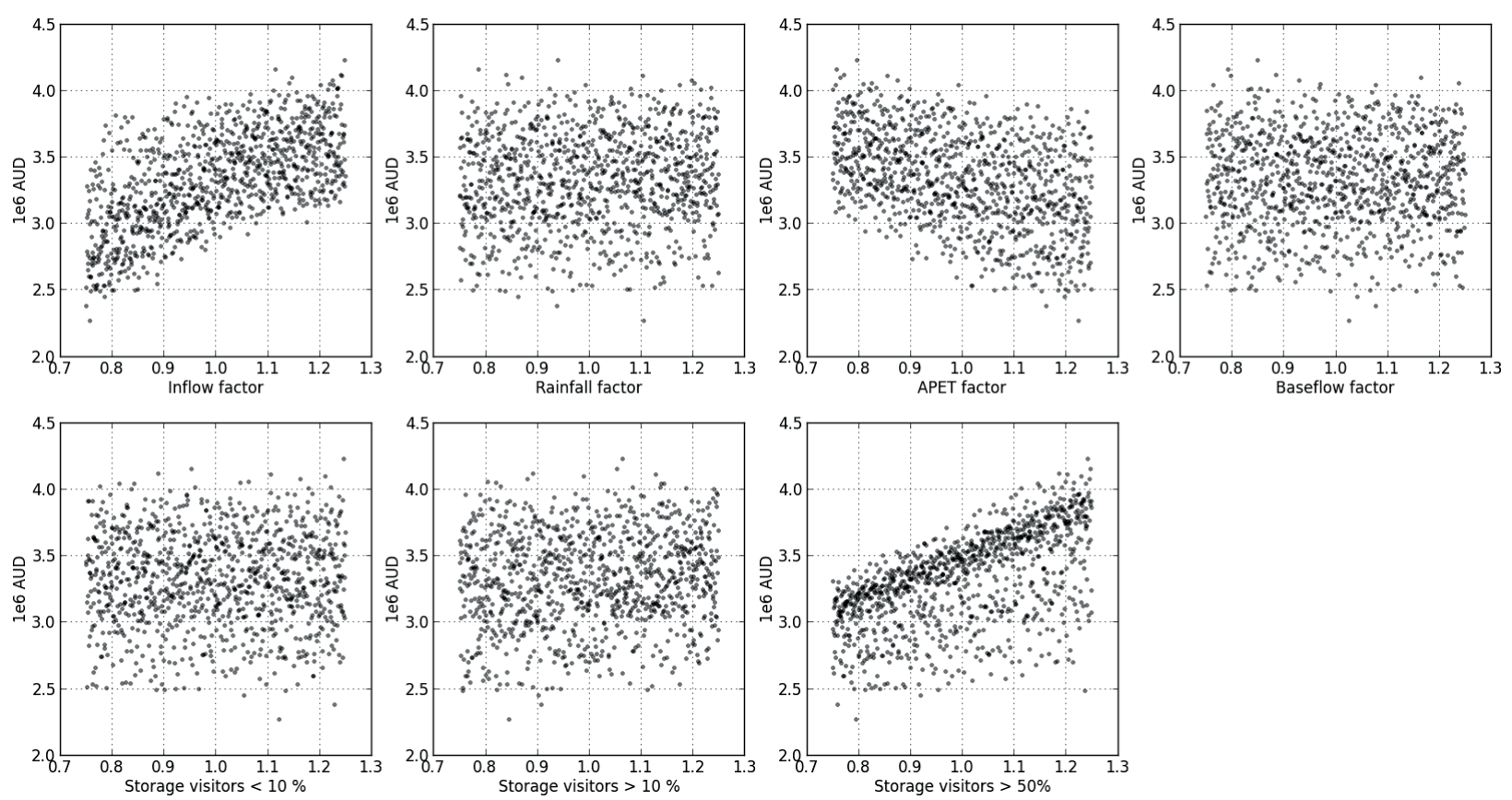

Fig. 4 Scatter plots of sensitivity analysis of the effect of selected driving variables and parameters on the total value generated by recreation on storage reservoirs. Shown on the $x$-axis are the multipliers with which the original model was modified.

It is apparent from Fig. 4 that the most influential parameters are the number of visitors when the storage reservoir is above $50 \%$ of full capacity, the inflow to the model and the evapotranspiration rate. The number of visitors when the reservoir is below $50 \%$ hardly affects the total value generated. Likewise, the rainfall in the river system and the baseflow are of minor importance for the total value generated from recreation. This sensitivity analysis provides a tool to prioritize further research and river management. It highlights the need to have an accurate estimate of streamflow entering the system to simulate the hydrological system.

\section{DISCUSSION AND CONCLUSIONS}

Most of water resource planning is concerned with understanding and managing risks, whether explicitly or implicitly. The adoption of ISO 31000:2009 provides a systematic procedure for risk- 
based water resource planning that is transparent, defensible and repeatable. Managing risks explicitly has the advantage that plans will be more robust and therefore planning objectives are more likely to be achieved.

The demonstration use case has given us the opportunity to trial the practicality of the approach, including the critical separation of (objective) analysis from (subjective) evaluation and the casting of mitigation/adaptation as model scenarios. Presentations of the approach has been well received by jurisdictions in the Murray-Darling Basin, although they have voiced concern that they will not be able to implement the method using the same sophistication as the demonstration use case (which uses high performance computing and professional software engineering). The use case has demonstrated that river system models can provide the backbone of risk assessment workflows as long as they can be conceptually and logically simplified to enable sensitivity and uncertainty analysis.

The use case, including mitigation/adaptation scenarios, and documenting the method as guidelines (Black et al. 2014) will be completed by mid 2014. To achieve a successful outcome, these need to be robustly road-tested with water agencies. In conclusion, results to-date endorse ISO 31000:2009 and the workflow paradigm as being fit-for-purpose for water resource planning. We hope, through this research, to make a significant and serious contribution to improving equitable and transparent water resource planning and the development of the next generation of water sharing plans in 2019.

Acknowledgements This work has been funded through the Integrated Water Resource Management theme of the CSIRO Water for a Healthy Country Flagship as one of CSIRO's contributions to improving water planning practices as required under the national water reform agenda.

\section{REFERENCES}

Black, D., et al. (2011) Guidelines for water management modelling: Towards best-practice model application. Version 1.0. eWater Cooperative Research Centre, Canberra. ISBN 978-1-921543-46-3.

Black D., Podger, G., and Cuddy, S. M. (2014) Guidelines on implementing risk management in water resource planning. Water for a Healthy Country Flagship report, CSIRO, Canberra (in draft).

CSIRO (2008) Water availability in the Murrumbidgee. A report to the Australian Government from the CSIRO MurrayDarling Basin Sustainable Yields Project. Canberra, Australia.

Cuddy, S. M. and Fitch, P. (2010) Hydrologists Workbench - a hydrological domain workflow toolkit. In: Proc of: IEMSs Fifth Biennial Meeting, Ottawa, Canada.

Dutta, D., et al. (2012) A daily river system model for the Murray-Darling Basin: development, testing and implementation, Proceedings of the 34th Hydrology and Water Resources Symposium, 1057-1066.

MDBA (2012) Water Act 2007 - Basin Plan 2012. Murray Darling Basin Authority, Canberra.

NSW Government (2012) Water Sharing Plan for the Murrumbidgee Regulated River Water Source 2003, NSW legislation.

NWC (2011) National Water Planning Report Card 2011. National Water Commission, Canberra.

Standards Australia (2009) AS/NZS ISO 31000:2009 Risk management-principles and guidelines. 24 pp.

Welsh, W. D., et al. (2013) An integrated modelling framework for regulated river systems. Environ. Model. Software 39, 81-102. 